\title{
PI3K/AKT signaling pathway: a possible target for adjuvant therapy in COVID-19
}

\author{
Mohammad Rafi Khezri ${ }^{1}$
}

Received: 28 December 2020 / Accepted: 31 December 2020 / Published online: 11 January 2021

(C) Japan Human Cell Society 2021

\section{To the editor}

Coronavirus disease 2019 (COVID-19), caused by the severe acute respiratory syndrome coronavirus-2 (SARSCoV-2), poses a major challenge to the world's healthcare systems. There is no definitive cure for this disease and the available treatments are used to suppress the symptoms. Molecular agents can be used to introduce possible drugs to treat this disease. One of the possible therapeutic targets is the phosphatidylinositol 3-kinase (PI3K)/AKT signaling pathway, which is involved in various aspects of virus entry into the cell and the development of immune responses. The relationship between this pathway and the entry of the virus into the cell must first be examined. There are two main receptors for the virus to enter the cell: angiotensin-converting enzyme 2 (ACE2) and CD147 [1]. The other molecular factors on the cell surface for entry of the viral genome to the host cell by non-endosomal pathway are TMPRSS2 and furin [1]. It has been demonstrated that activation of both CD147 and furin contributes to inducing the PI3K/ AKT signaling pathway $[1,2]$. Once the virus binds to the ACE2, its endocytosis occurs with the virus [3]. It has been shown that SARS-CoV-2 endocytosis occurs through a clathrin-mediated pathway which is regulated by the PI3K/ AKT signaling [1]. It has been indicated that suppression of this pathway has inhibited the entry of other viruses that use clathrin-mediated endocytosis [4]. The reduction of ACE2 at the cell surface contributes to an increase in the serum levels of angiotensin II (Ang II), which has been shown in COVID-19 patients [5]. Elevated serum levels of Ang II increase inflammatory cytokines such as IL-6 and TNF- $\alpha$ which their high levels have been shown in COVID19 patients [5]. Additionally, it has been demonstrated that

Mohammad Rafi Khezri

Drmnkh76@gmail.com

1 Department of Pharmacology and Toxicology, Faculty of Pharmacy, Urmia University of Medical Sciences, Sero Road, 5715799313 Urmia, Iran
Ang II induces different organs' fibrosis [5]. These effects seen from Ang II can be related to the PI3K/AKT signaling pathway, since binding of Ang II to its receptor, angiotensin II receptor type 1 (AT1R), causes activation of this pathway [6]. On the other hand, activation of the PI3K/AKT signaling pathway has been linked to the induction of lung tissue fibrosis, which has been detected in patients with COVID-19 $[5,7]$. Regarding the role of this pathway in inducing inflammation, we can mention the activation of factors such as activated protein-1 (AP-1) and nuclear factor kappa B (NF$\kappa B)$ [8]. Various studies have shown that suppression of the $\mathrm{PI} 3 \mathrm{~K} / \mathrm{AKT}$ signaling pathway inhibits NF- $\mathrm{KB}$ and AP-1 and ultimately reduces the expression of inflammatory cytokines such as IL-6 and TNF- $\alpha$ [9]. Based on this evidence, the use of drugs, such as azithromycin, which have been shown to inhibit PI3K/AKT signaling pathway and ultimately suppress inflammation [10], along with antiviral drugs to combat COVID-19 can be considered.

\section{Compliance with ethical standards}

Conflict of interest There is no conflict of interest to declare.

\section{References}

1. Lokhande AS, Devarajan PV. A review on possible mechanistic insights of Nitazoxanide for repurposing in COVID-19. Eur J Pharmacol. 2021;891:173748. https://doi.org/10.1016/j.ejpha r.2020.173748.

2. He Z, Khatib A-M, Creemers JW. Loss of proprotein convertase furin in mammary gland impairs proIGF1R and proIR processing and suppresses tumorigenesis in triple negative breast cancer. Cancers. 2020;12(9):2686.

3. Lukiw WJ, Pogue A, Hill JM. SARS-CoV-2 infectivity and neurological targets in the brain. Cell Mol Neurobiol. 2020. https:// doi.org/10.1007/s10571-020-00947-7.

4. Cheng CY, et al. Cell entry of bovine ephemeral fever virus requires activation of S rc-JNK-AP 1 and PI 3 K-A kt-NF- $\kappa$ B 
pathways as well as C ox-2-mediated PGE 2/EP receptor signalling to enhance clathrin-mediated virus endocytosis. Cell Microbiol. 2015;17(7):967-87.

5. Miesbach W. Pathological role of angiotensin II in severe COVID19. TH Open. 2020;4(2):e138.

6. Du N, et al. Angiotensin II receptor type 1 blockers suppress the cell proliferation effects of angiotensin II in breast cancer cells by inhibiting AT1R signaling. Oncol Rep. 2012;27(6):1893-903.

7. Zhang XL, et al. PI3K/Akt signaling is involved in the pathogenesis of bleomycin-induced pulmonary fibrosis via regulation of epithelial-mesenchymal transition. Mol Med Rep. 2016;14(6):5699-706.

8. Lee I-T, Yang C-M. Inflammatory signalings involved in airway and pulmonary diseases. Mediators Inflamm. 2013;2013:791231. https://doi.org/10.1155/2013/791231.
9. Yodkeeree $\mathrm{S}$, et al. O-methylbulbocapnine and dicentrine suppress LPS-induced inflammatory response by blocking NF- $\mathrm{\kappa B}$ and AP-1 activation through inhibiting MAPKs and Akt signaling in RAW264.7 macrophages. Biol Pharm Bull. 2018;41(8):1219-27.

10. Sun X, Chen L, He Z. PI3K/Akt-Nrf2 and anti-inflammation effect of macrolides in chronic obstructive pulmonary disease. Curr Drug Metab. 2019;20(4):301-4.

Publisher's Note Springer Nature remains neutral with regard to jurisdictional claims in published maps and institutional affiliations. 